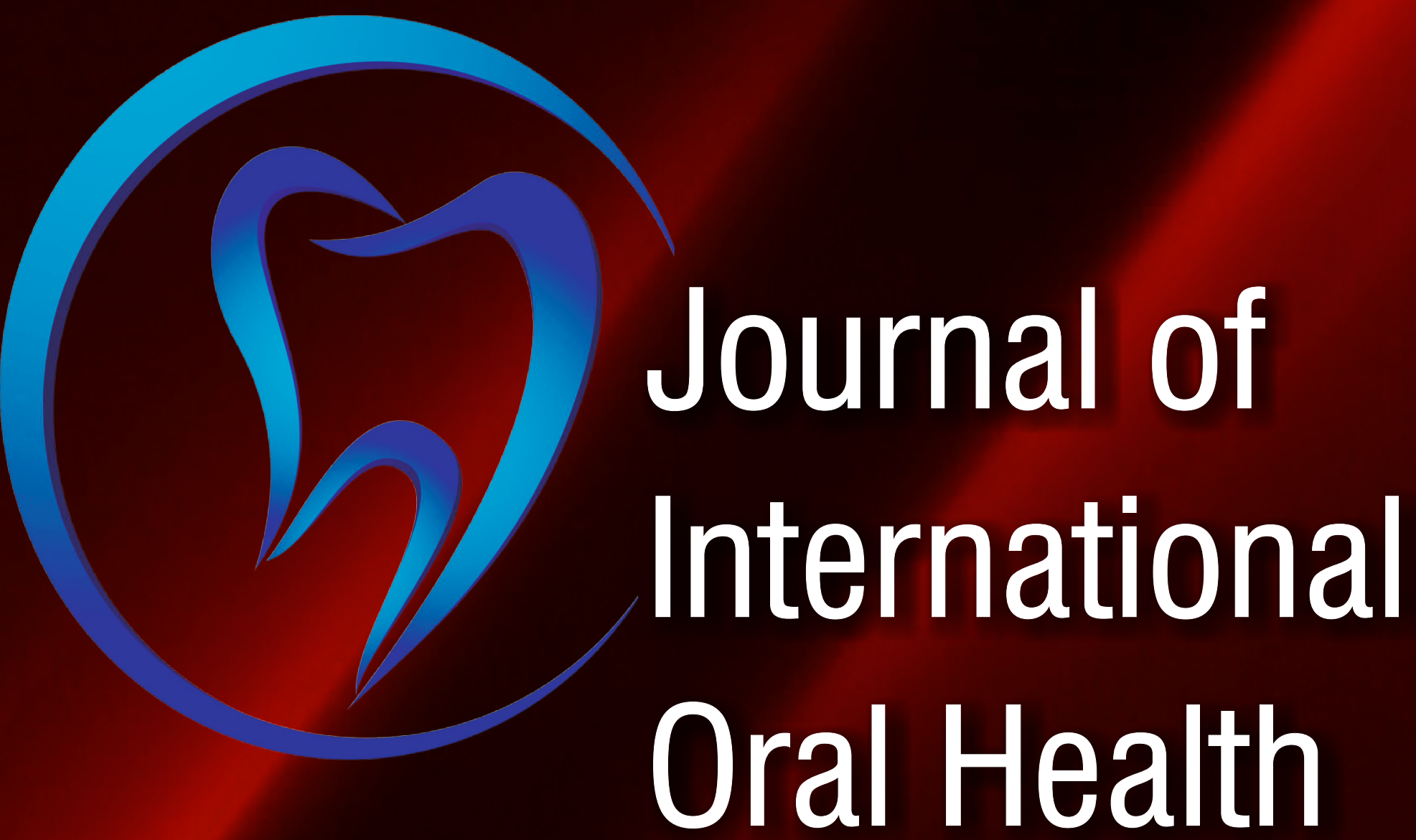

International Society of Preventive and Community Dentistry

Volume 11 - Issue 2 • March-April 2019

www.jioh.org 


\title{
Correlation of Maxillary and Mandibular Arch form and Tooth Size Ratio in Ethnic Javanese Malocclusion Patient
}

\author{
I Gusti Aju Wahju Ardani', Dhansha Kannayyah², Ari Triwardhani ${ }^{1}$ \\ ${ }^{1}$ Department of Orthodontics, Faculty of Dental Medicine, ${ }^{2}$ Undergraduate Student, Faculty of Dental Medicine, Airlangga University, Surabaya, Indonesia
}

\section{Abstract}

\begin{abstract}
Aims: Arch form is one of the important components that can relapse after orthodontic treatment. The relationship is between arch form and tooth size ratio (TSR) need to be evaluated that could help to determine extraction or nonextraction treatment in malocclusion. The aim of this study was to analyze the correlation of maxillary and mandibular arch forms with TSR in ethnic Javanese Malocclusion Patient at Airlangga University Dental Hospital. Materials and Methods: This study was an observational, analytical study with cross-sectional and total sampling method. The samples consisted of 135 model study were chosen according to the inclusion criteria and distributed into malocclusion Class I, Class II, and Class III Angle's classification. All the samples were analyzed using Bolton's anterior and overall ratio, and the maxillary and mandibular arch forms were detected using mathematical ratio using (canine depth/molar depth (MD))/(canine width [CW]/molar width [MW]). Statistical Analysis: The correlation of maxillary and mandibular arch form with clinically significant TSR using Bolton's analysis is interpreted using Pearson correlation test $(P<0.05)$. Results: No significant correlation of maxillary and mandibular arch forms with TSR using Bolton's analysis among malocclusion of Angle Class I, Class II, and Class III in ethnic Javanese $(P>0.05)$ was found. While the anterior TSR in Class I Angle's malocclusion has a significant correlation with inter-CW in mandibular arch $(P<0.05)$. Conclusions: TSR was not affected by types of arch form either in maxillary or mandibular while the anterior TSR in Class I Angle's malocclusion did.
\end{abstract}

Keywords: Arch form shape, Bolton's analysis, ethnic Javanese, malocclusion, tooth size ratio

\section{INTRODUCTION}

Analysis of the study model is one of the undeniable procedures in orthodontic to interpret diagnosis and treatment planning for patients with different malocclusion. The analysis of study model has been used for three-dimensional evaluation in the upper and lower arch forms with the relationship of occlusal which can be calculated by mean of analysis using arch length, arch form dimension, and mesiodistal tooth size ${ }^{[1,2]}$ Malocclusion can be diagnosed if there is a discrepancy or surplus of tooth material either in maxillary arch form or mandibular arch form. ${ }^{[3,4]}$

According to Bolton, tooth size ratio (TSR) estimation is crucial for treatment planning in orthodontics. ${ }^{[5]}$ Many investigators found that Bolton's ideal TSR is varied and affected by different population, genetic, malocclusion, and gender ${ }^{[6-9]}$ Shahab et al. found that Bolton's TSR varied among the Turkish population and the most difference was found on the first molar size. ${ }^{[10]}$

\begin{tabular}{|l|l|}
\hline \multicolumn{3}{|c|}{ Access this article online } \\
\hline Quick Response Code: & Website: \\
& www.jioh.org \\
& \\
&
\end{tabular}

Smith et al. found that there was significantly different overall TSR among three different populations which are Hispanics (93.1\%), Asian (92.3\%), and African (93.4\%) that showed interarch tooth size relationships are population specific. ${ }^{[11,12]}$ Kusnoto found that there was difference in the overall and anterior TSR among the Indonesian population and Caucasian population. He found that among the Indonesian population, the Bolton TSR value of $89.7 \pm 2.05$ for overall ratio and $76.4 \pm 2.76$ for the anterior ratio is more suitable. ${ }^{[13]}$

The arch form before the treatment is fundamental in orthodontic treatment planning. The pretreatment adjusted through the skeletal base and soft tissues which might be determined by genetic and environmental factors. ${ }^{[14]}$ All the changes during pretreatment should be assessed as amending in

Address for correspondence: Dr. I Gusti Aju Wahju Ardani, Faculty of Dental Medicine, Airlangga University, Surabaya, Indonesia. E-mail: wahju_ardani@fkg.unair.ac.id

This is an open access journal, and articles are distributed under the terms of the Creative Commons Attribution-NonCommercial-ShareAlike 4.0 License, which allows others to remix, tweak, and build upon the work non-commercially, as long as appropriate credit is given and the new creations are licensed under the identical terms.

For reprints contact: reprints@medknow.com

How to cite this article: Ardani IG, Kannayyah D, Triwardhani A. Correlation of maxillary and mandibular arch form and tooth size ratio in ethnic Javanese malocclusion patient. J Int Oral Health 2019;11:75-9. 
arch form during treatment as a whole estimated as potentially unstable and quantized. ${ }^{[15]}$ Tooth size shows a substantial relation with inheritance, and in the study of Harris found that the contribution of genetic component to mesiodistal and buccolingual crown circumference is $>80 \%{ }^{[11]}$ The study of Cassidy found that the influence of genetic on the dental arch form from 320 orthodontic patients and found that the size of arch and arch shape (length-width ratio) possess an average genetic component. ${ }^{[16]}$

So far, the correlation between the dimensions of the anterior teeth and their corresponding arch forms has only been evaluated in one study. A statistically significant relation between broad and sharp or tapered maxillary arch forms with smaller tooth sizes was detected among 200 Greek individuals seeking orthodontic treatment, but this was more commanding among male samples. In Addition, a statistically significant relationship was found between tappered maxilla arch forms and smaller teeth in female patient. Nevertheless, tooth size discrepancy was found in previous study ${ }^{[9]}$ Therefore, the relationship between tooth size discrepancy (TSD) and arch form has not been studied as yet. This study hypothesis was no correlation exists between maxillary and mandibular arch form and TSR using Bolton's analysis in patients with malocclusion Class I, Class II, and Class III. Furthermore, the objective of this study was to evaluate the correlation of upper and lower arch forms with TSR in ethnic Javanese Patient Malocclusion Patient at Airlangga University Dental Hospital.

\section{Materials and Methods}

This study was an observational analytical retrospective study with cross-sectional and total sampling method. A total of 135 study models from ethnic Javanese with the age range of 12-26 were selected from Orthodontic Clinic Department, Faculty of Dental Medicine, Airlangga University, according to the inclusion and exclusion criteria of the study. The study models divided into three major Angle's classifications of malocclusion as follows: Group 1 (Class I malocclusion), Group II (Class II malocclusion), and Group III (Class III malocclusion). Each class of malocclusion was analyzed equally using Bolton's overall and anterior ratio, and maxillary and mandibular arch forms were interpreted using mathematical method.

The width of mesiodistal of each tooth is measured using digital Vernier caliper with 0.01 least count (Gauge Block No. 020048) [Figure 1]. Anterior TSR was calculated using total of mesiodistal (MD) width of six anterior teeth using the formula:

$$
\text { Anterior ratio }=\frac{\text { Total MD width of mandibular } 6 \text { teeth }}{\text { Total MD width of maxillary } 6 \text { teeth }} \times 100
$$

Overall ratio $=\frac{\text { Total MD width of mandibular } 12 \text { teeth }}{\text { Total MD width of maxillary } 12 \text { teeth }} \times 100$

Dimension of arch form, which is intercanine width (ICW), interpremolar width (IPW), intermolar width (IMW), intercanine depth (CD), interpremolar depth (PD), and intermolar depth, was calculated using the Vernier caliper according to the anatomy landmark marked at the study model [Figure 2]. ${ }^{[17]}$

The calculated arch form dimension was used to interpret the shape of the arch form using a mathematical formula (canine depth/Molar Depth (MD))/(CW/MW) [Figure 3]. ${ }^{[17]}$

1. ICW - The interspace between the cusp tips of right and left canines

2. IPW - The interspace between the right and left first premolars, measured from the tip of the first premolar tooth

3. IMW - The interspace between the highest point on the mesiobuccal cusp tips of the right and left first molars

4. $\mathrm{CD}-\mathrm{The}$ interspace from a line adjoining the canines to the midpoint between the central incisors

5. PD - The interspace from a line adjoining the first premolars to the midpoint between the central incisors

6. Molar depth (MD): The interspace from a line adjoining the first molars to the midpoint between the central incisors.

All data were analyzed statistically using the Statistical Package for the Social Sciences (SPSS) software version 25 (IBM Coporation, Illinois, Chicago, USA). The distribution of data was tested using the One-Sample KolmogorovSmirnov test $(P>0.05)$. The correlation of arch form dimensions and Bolton's TSR was analyzed using Pearson Correlation test $(P<0.05)$. In addition, one-way analysis of variance $(P<0.05)$ was used for the comparisons between different types of arch form and the Bolton's TSR.

\section{RESULTS}

Class 1 malocclusion was the most prevalent in our study [Table 1]. The most prevalent arch form in maxilla was tapered while in mandibular was square [Table 2]. Differences in the mean value of Bolton's TSR according to arch form in the maxilla and mandibular in all three major Angle's malocclusions are shown in Table 3. There was no statistically significant correlation between arch form and TSR (anterior and overall) in the maxilla and mandibular among Class II and Class III malocclusions. However, this study found that there were inadequate correlation between TSR and arch form in maxilla among Malocclusion Class I.

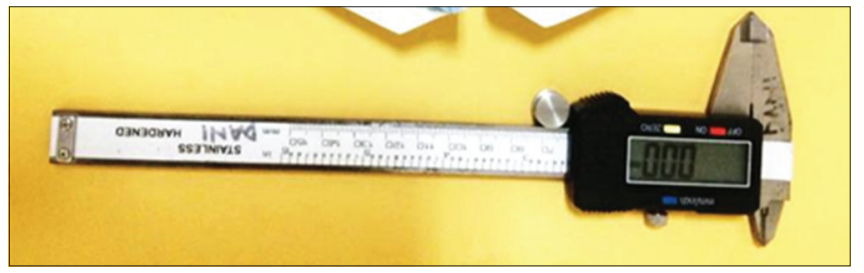

Figure 1: Digital vernier caliper with 0.01 least count (Gauge Block No. 020048) 


\section{Discussion}

In the present study, there was no significant correlation between TSR and arch form in Ethnic Javanese maloclussion patient. Nevertheless, there was weak correlation between anterior TSR and arch form in maxilla among malocclusion Class I. The same result was found with the recent study of O'Mahony et al., about the relationship between TSD and arch form among different types of malocclusions. ${ }^{[18]}$

In this study, we classified the malocclusion according to angle, but this study did not take the consideration of Class II Division I, Division II, subdivision and Class III pseudo, true, and subdivision. This is because there is lack of samples in each subdivision to get a significant result.

Among Ethnic Javanese, we found that the most common maxillary arch form was square in malocclusion Class I, tapered in Class II and Class III, whereas in the mandibular arch form, the most common arch form found is square in all three classes of malocclusion Class I, Class II, and Class III. The most common maxillary tapered arch form among malocclusion Class II has the same result as in the study of Olmez et al., and the most common mandibular square arch form among Class III has the same result as Slaj study. ${ }^{[18,19]}$

In the recent study by Omar among a Saudi samples in Class I, Class II, and Class III cases, the most prevalent arch form was narrow tapered, followed by narrow ovoid and the upper arch

\section{Table 1: The distribution of total samples into respective malocclusion classification}

\begin{tabular}{lc}
\hline Angle's classification of malocclusion & Study samples \\
\hline Class I & 54 \\
Class II & 24 \\
Class II subdivision & 25 \\
Class III & 22 \\
Class III subdivision & 10 \\
Total Sampels & 135 \\
\hline
\end{tabular}

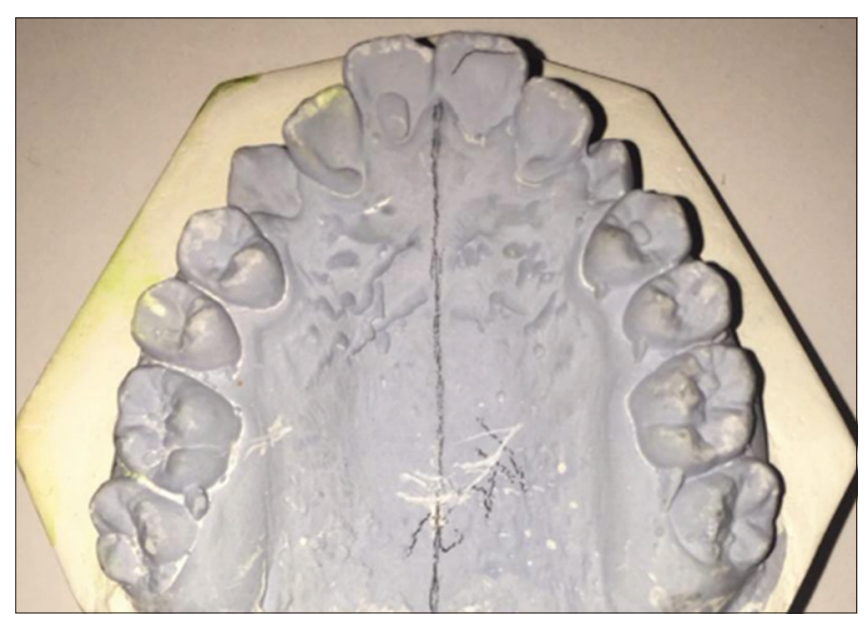

Figure 2: The linear width and depth measurements of arch dimensions form did not match the lower arch form, especially in Class II and Class III cases. ${ }^{[20]}$

Tubercle sharp end and incisal edges are used as landmarks in most of the conventional studies, in identifying the arch form. In our study, we used the same technique to determine the anatomy landmarks on study models. ${ }^{[21]}$ In this study, we used mathematical formula to interpret the shape of the arch from which is square, ovoid, and tapered which is the form of human dental arch has been used traditionally as in the study. According to McLaughlin and Bennet, relative ratios of the canine and MW along with their relative arch depth were used to relate the arch form. When the CW/MW ratio increases and the $\mathrm{CD} / \mathrm{MD}$ ratio decreases, the arch becomes squarer. ${ }^{[22]}$ However, when the CW/MW ratio decreases and $\mathrm{CD} / \mathrm{MD}$ ratio increases, the arch gets a more pointed form according to Budiman's study. ${ }^{[2]}$ When compare the Bolton's TSR among the three classes, Class I and Class III are showing bigger mean value of Bolton's TSR. The same result was found with the study of Wedrychowska where the anterior TSR in Class I was $79.1 \pm 2.2$ while $80.1 \pm 3.0$ in Class III. ${ }^{[23]}$ In the present study found that Malocclusion Class I has greater anterior TSR mean than another malocclusion types, meanwhile overall TSR mean was still in normal range. It can be explained that, in Class I, the anterior tooth material is greater in mandibular anterior or there was a discrepancy in the tooth size material in maxilla anterior teeth. ${ }^{[5]}$ Whereas in the study of Abdul Jamih et al, among South indian population found that the total anterior tooth ratio was greater than the Bolton's tooth ratio for all angles malocclusions among and the results exhibited there is total increased mandibular tooth excess. ${ }^{[24]}$

In Class III, the anterior and overall TSR showed a bigger value than normal may assure the results from the study of

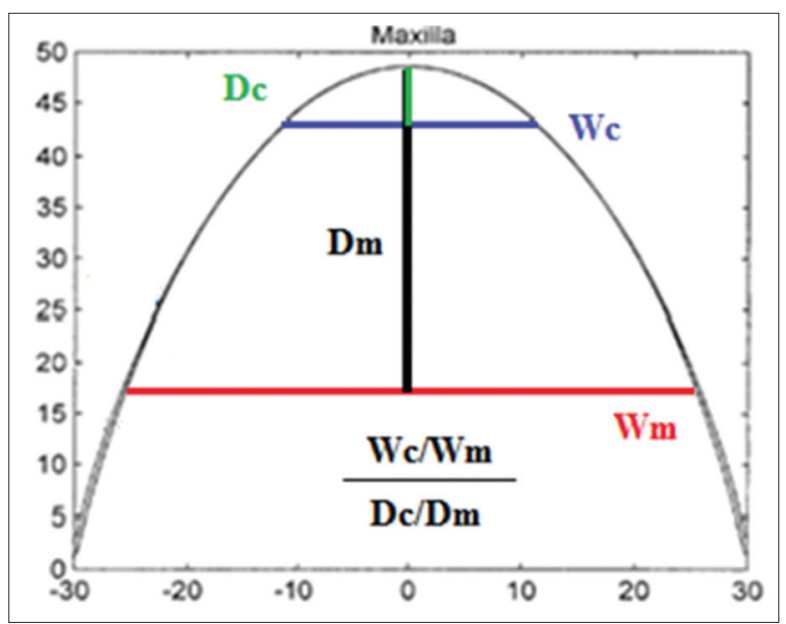

Figure 3: The calculated arch form dimension was used to interpret the shape of arch form by using a mathematical formula (CD/MD)/ (CW/MW). ${ }^{[17]}$ CD: Canine depth, MD: Molar depth, CW: Canine Width, and MW: Molar Width. When the Wc/Wm ratio increases of the Dc/Dm ratio decreases, the arch becomes squarer. On the contrary, when Wc/Wm ratio decreases or Dc/Dm ratio increases, the arch gets a more tapered form. Therefore, the formula is used to describe the arch form 
Table 2: Differences in the mean value of Bolton's TSR according to arch form in maxilla and mandibular in all three major Angle's malocclusions (Descriptive One-way ANOVA test

\begin{tabular}{|c|c|c|c|c|c|c|c|c|c|}
\hline \multicolumn{5}{|c|}{ Maxilla } & \multicolumn{5}{|c|}{ Mandibular } \\
\hline Malocclusion & Bolton's TSR & Arch form & $n$ & Mean value & Malocclusion & Bolton's TSR & Arch form & $n$ & Mean value \\
\hline \multirow[t]{8}{*}{ Class I } & Anterior & square & 22 & 80.1682 & & & square & 33 & 78.6970 \\
\hline & & ovoid & 17 & 76.6471 & & Anterior & ovoid & 11 & 794364 \\
\hline & & tapered & 15 & 80.8933 & Class I & & tapered & 10 & 80.9300 \\
\hline & & Total & 54 & 79.2611 & & & Total & 54 & 79.2611 \\
\hline & Overall & square & 22 & 91.6136 & & & square & 33 & 91.2091 \\
\hline & & ovoid & 17 & 91.1665 & & & ovoid & 11 & 93.4300 \\
\hline & & tapered & 15 & 93.1480 & & Overall & tapered & 10 & 92.4920 \\
\hline & & Total & 54 & 91.8991 & & & Total & 49 & 90.7592 \\
\hline \multirow[t]{11}{*}{ Class II } & Anterior & square & 11 & 78.2818 & & & square & 21 & 77.9810 \\
\hline & & ovoid & 9 & 76.4889 & & Anterior & ovoid & 8 & 78.2250 \\
\hline & & tapered & 29 & 79.3241 & & & tapered & 20 & 79.3250 \\
\hline & & Total & 49 & 78.5694 & Class II & & Total & 49 & 78.5694 \\
\hline & Overall & square & 11 & 91.9455 & & & square & 21 & 91.8190 \\
\hline & & ovoid & 9 & 92.1667 & & Overall & ovoid & 8 & 91.1750 \\
\hline & & tapered & 29 & 89.8724 & & & tapered & 20 & 89.4800 \\
\hline & & Total & 49 & 90.7592 & & & Total & 49 & 90.7592 \\
\hline & & square & 6 & 77.9900 & & & square & 16 & 78.7400 \\
\hline & & ovoid & 10 & 80.6600 & & Anterior & ovoid & 8 & 83.2875 \\
\hline & Anterior & tapered & 16 & 81.7688 & & & tapered & 8 & 82.0875 \\
\hline \multirow[t]{5}{*}{ Class III } & & Total & 32 & 80.7138 & & & Total & 32 & 80.7138 \\
\hline & & square & 6 & 94.5167 & Class III & & square & 16 & 93.4187 \\
\hline & & ovoid & 10 & 93.6700 & & Overall & ovoid & 8 & 96.3625 \\
\hline & Overall & tapered & 16 & 95.9563 & & & tapered & 8 & 96.6875 \\
\hline & & Total & 32 & 94.9719 & & & Total & 32 & 94.9719 \\
\hline
\end{tabular}

\begin{tabular}{|c|c|c|c|c|c|c|c|}
\hline Malocclusion & TSR & Comparison & Sum of Squares & df & Mean Square & $F$ & $P$ \\
\hline \multirow[t]{6}{*}{ Class I } & Anterior & Between Groups & 174.229 & 2 & 87.114 & 3.617 & $0.034 *$ \\
\hline & & Within Groups & 1228.359 & 51 & 24.085 & & \\
\hline & & Total & 1402.588 & 53 & & & \\
\hline & Overall & Between Groups & 34.314 & 2 & 17.157 & 1.340 & 0.271 \\
\hline & & Within Groups & 652.866 & 51 & 12.801 & & \\
\hline & & Total & 687.179 & 53 & & & \\
\hline \multirow[t]{6}{*}{ Class II } & Anterior & Between Groups & 56.386 & 2 & 28.193 & 0.827 & 0.444 \\
\hline & & Within Groups & 1568.738 & 46 & 34.103 & & \\
\hline & & Total & 1625.124 & 48 & & & \\
\hline & Overall & Between Groups & 56.113 & 2 & 28.057 & 0.563 & 0.573 \\
\hline & & Within Groups & 2292.085 & 46 & 49.828 & & \\
\hline & & Total & 2348.198 & 48 & & & \\
\hline \multirow[t]{6}{*}{ Class III } & Anterior & Between Groups & 62.350 & 2 & 31.175 & 1.038 & 0.367 \\
\hline & & Within Groups & 870.749 & 29 & 30.026 & & \\
\hline & & Total & 933.100 & 31 & & & \\
\hline & Overall & Between Groups & 33.696 & 2 & 16.848 & 0.774 & 0.471 \\
\hline & & Within Groups & 631.609 & 29 & 21.780 & & \\
\hline & & Total & 665.305 & 31 & & & \\
\hline
\end{tabular}

Lavelle (1972) that Class III individuals patient have irregular smaller upper teeth than Class I and Class II patient, and from the value, it can be interpreted either there was significant bigger tooth size material in mandibular or severe discrepancy in tooth size in maxilla. ${ }^{[23]}$ In our study, malocclusion Class II showed a normal range value of anterior and overall TSR. The higher value of anterior and overall TSR among Class III malocclusion can be correlated by a gradual increase in the width of the anterior upper teeth or the cumulative of minor discrepancies of individual teeth. ${ }^{[5,22]}$ 
There was significant negative correlation between anterior TSR from Bolton analysis and mandibular ICW in malocclusion Class I. This showed that if mandibular ICW increases, anterior Bolton's TSR decreases. This indicated that, if the mandibular intercanine expands, there will be high changes of higher tooth material in maxillary anterior teeth or discrepancy in the anterior mandibular teeth. ${ }^{[5,22,25]}$

The study of Al-Khateeb et al. and O'Mahony et al. found that there was no any significant correlation between arch form and TSD. ${ }^{[6,18]}$ There was indirect relationship between arch form and TSD which was validated in the study of Gaidyte and Baubiniene where found that arch form dimension influenced by Bolton's index..$^{[26]}$

The current study was carried out among orthodontic patients, hence the distribution of malocclusion are not representative of general population characteristics. Patient's ethnicity was recognized on their self-reporting during questionnaire section and not tracing the ancestry or genealogical pool. We also categorized malocclusion based only molar relationship which is according to Angle's classification of malocclusion and it could be different from the underlying skeletal relationship which we did not take heed in our study. Upcoming studies may consider these limitations in mind and handle them while designing their research methodology.

\section{Conclusions}

There was no significant correlation between maxillary and mandibular arch form and TSR using Bolton's analysis among three major malocclusions, while there was a negative correlation between anterior TSR from Bolton's analysis and mandibular ICW in malocclusion Class I that can be used to interpret the orthodontic treatment plan in ethnic Javanese malocclusion patient.

\section{Financial support and sponsorship}

Nil.

\section{Conflicts of interest}

There are no conflicts of interest.

\section{RefEREnCES}

1. English JD, Sercan A, Timo P, Kate L. Mosby's Orthodontic Review. St Louis, Missouri: Elsevier; 2015. p. 39.

2. Reuschl RP, Heuer W, Stiesch M, Wenzel D, Dittmer MP. Reliability and validity of measurements on digital study models and plaster models. Eur J Orthod 2016;38:1:22-6.

3. Fattahi HR, Pakshir HR, Hedayati Z. Comparison of tooth size discrepancies among different malocclusion groups. Eur J Orthod 2006;28:491-5.

4. Uysal T, Memili B, Usumez S, Sari Z. Dental and alveolar arch widths in normal occlusion, class II division 1 and class II division 2. Angle
Orthod 2005;75:941-7.

5. Bolton WA. The clinical application of tooth-size analysis. Am J Orthod 1962;48:504-29.

6. Al-Khateeb SN, Abu Alhaija ES. Tooth size discrepancies and arch parameters among different malocclusions in a Jordanian sample. Angle Orthod 2006;76:459-65.

7. Zia M, Azad AA, Ahmed S. Comparison of distance between maxillary central incisors and incisive papilla in dentate individuals with different arch forms. J Ayub Med Coll Abbottabad 2009;21:125-8.

8. Saleem T. Incisive Papilla-Maxillary Central Incisor Distance in Subjects of Various Arch and Face Forms. Karachi: College of Physians and Surgeons Pakistan; 2007.

9. Haralabakis NB, Sifakakis I, Papagrigorakis M, Papadakis G. The correlation of sexual dimorphism in tooth size and arch form. World $\mathrm{J}$ Orthod 2006; 7:254-60.

10. Jan A, Bangash AA, Adil S, Arhab SS, Khalid Z, Pasha H. Comparison of bolton ratio between two ethnic groups reporting to armed forces institute of dentistry (afid) rawalpindi. Pak Armed Forces Med J 2016; 66:75-8.

11. Harris EF, Smith RJ. A study of occlusion and arch widhts in in study models of non-extraction orthodontic families. Am J Orthod 1980;78:155-63.

12. Terrez YC, Fitzmaurice OS. Tejada HEP. Pont's index in study models of patients who finished a non-extraction orthodontic treatment at the Orthodontic Clinic of the Postgraduate Studies and Research Division of the National University of Mexico. Revista Mexicana de Ortodonsia 2013;1:7-12.

13. Kusnoto J. The Reliability of The Bolton ratio when applied to the Indonesian population. Asian J Pharm Clin Res 2017;10:176.

14. McNamara C, Drage KJ, Sandy JR, Ireland AJ. An evaluation of clinicians' choices when selecting archwires. Eur J Orthod 2010;32:54-9.

15. Hnat WP, Braun S, Chinhara A, Legan HL. The relationship of arch length to alterations in dental arch width. Am J Orthod Dentofacial Orthop 2000;118:184-8.

16. Cassidy KM, Harris EF, Tolley EA, Keim RG. Genetic influence on dental arch form in orthodontic patients. Angle Orthod 1998;68:445-54.

17. Al-Shammout RWK, Al-Jabrah OA, Aburumman KK, Alhabahbah AM, Almanaseer WA. The Effect of Various Classes of Malocclusions on the Maxillary Arch Forms and Dimensions in Jordanian Population. Adv Dent Oral Health. 2016;2:1-7.

18. O'Mahony G, Millett DT, Cronin MS, McIntyre GT, Barry MK. The relationship between tooth size discrepancy and archform classification in orthodontic patients. J Clin Exp Dent 2015;7:e268-72.

19. Olmez S, Dogan S. Comparison of the arch form and dimensions in various malocclusions of the Turkish population. Open J Stomatol 2011;1:158-64.

20. Omar H, Alhajrasi M, Felemban N, Hassan A. Dental arch dimensions, form and tooth size ratio among a Saudi sample. Saudi Med J 2018;39:86-91.

21. Budiman J. Mathematical ratio in defining arch form. Dent Hypotheses 2017;8:70

22. McLaughlin RP, Bennet JC. Arch form considerations for stability and esthetics. Rev Esp Orthod 1999;29:46-63.

23. Wedrychowska-Szulc B, Janiszewska-Olszowska J, Stepień P. Overall and anterior Bolton ratio in class I, II, and III orthodontic patients. Eur J Orthod 2010;32:313-8.

24. Jamih A, Khimjmatgar S, Shetty V, Nayak US, Chowdhury C. Boltons ratio among South Indian population. Oral Health Dent 2018;3:520-7.

25. Abdalla Hashim AH, Eldin AH, Hashim HA. Bolton tooth size ratio among Sudanese Population sample: A preliminary study. J Orthod Sci 2015;4:77-82.

26. Gaidyte A, Baubiniene D. Influence of premolar extractions on tooth size discrepancy. Part two: Analysis of Bolton values. Stomatologija 2006;8:25-9. 